\title{
El hallazgo de un cañón en el Bajo Xingú. Patrimonio, identidad y tierra
}

The discovery of a cannon in the Lower Xingu: heritage, identity and land

Pablo lbáñez Bonillo

Universidad Pablo de Olavide. España

panamsb@hotmail.com

\section{MINORÍAS ÉTNICAS, PROCESOS DE GLOBALIZACIÓN Y CONTEXTOS URBANOS \\ MONOGRÁFICO COORDINADO POR JOSÉ Mํ VALCUENDE (Univ. Pablo de Olavide) e ISRAEL S. IDROVO LANDY (Univ. de Cuenca, Ecuador)}

\section{RESUMEN}

El hallazgo de un viejo cañón a orillas del río Xingú en el año 2013 provocó reacciones opuestas entre los distintos actores colectivos del municipio de Porto de Moz. A partir de las entrevistas y observaciones realizadas durante los días de su descubrimiento, este artículo reflexiona sobre el proceso de patrimonialización al que se vio sometido el objeto por todas las partes en conflicto. De la misma manera, en el presente texto se analizan las implicaciones del cañón como objeto ya patrimonializado en los debates sobre la identidad y la propiedad de la tierra en esta región del Bajo Amazonas, conectando el caso concreto con las problemáticas comunes de las poblaciones ribereñas y quilombolas en la Amazonia brasileña.

\section{ABSTRACT}

The discovery of a cannon at the Xingu River in 2013 triggered opposing reactions among the different actors of the Brazilian locality of Porto de Moz. Through the interviews and observations that were undertaken at the time, this work analyses the patrimonialization process of the cannon. In addition, the text also analyses the implications of the cannon, as a piece of heritage, in the local debates regarding identity and land property in this region of the Lower Amazon. The objective of the study is to link this particular case with the common struggles of the ribeirinho and quilombolas societies in the Brazilian Amazon.

PALABRAS CLAVE

patrimonio | identidades amazónicas | Porto de Moz

KEYWORDS

heritage | amazon identities | Porto de Moz

\section{Introducción}

El mes de junio de 2013 el municipio de Porto de Moz fue sorprendido por la inesperada aparición de un herrumbroso cañón. Yo me encontraba en la región recopilando datos para mi tesis doctoral sobre la conquista portuguesa del siglo XVII y, sin pretenderlo, me vi involucrado en la tumultuosa irrupción de aquel objeto. Lo que sucedió a continuación podría definirse como una de aquellas "situaciones sociales" a las que se refería Max Gluckman y que permiten, a partir de un acontecimiento determinado, el análisis del haz de relaciones que mantiene unidos a los distintos miembros de una comunidad. Si Gluckman (1940) estudió en su célebre artículo la inauguración de un puente en una colonia británica del continente africano, en el presente texto voy a tratar de reconstruir las reacciones encontradas que provocó el descubrimiento de aquel cañón. A partir de las entrevistas y observaciones realizadas durante los días del descubrimiento, trataré de ensayar algunas propuestas sobre la construcción de patrimonio e identidades entre los distintos grupos que conviven en la región del bajo Xingú. Mediante este caso concreto pretendo reflexionar sobre los derechos de las minorías y la propiedad de la tierra en la Amazonia brasileña, problema fundamental en la historia reciente de la región.

Partiré aquí de una noción construida y dinámica de las identidades colectivas en el marco de una negociación social siempre conflictiva. Estas tensiones serán percibidas a partir de las diversas estrategias patrimoniales que suscitó la aparición del cañón, así como por el debate ideológico sobre el desarrollo económico y la conservación del bosque tropical amazónico. En ese sentido, me interesa trascender el escenario municipal para insertar las discusiones aquí reconstruidas en el marco de una 
problemática mucho más amplia que no se detiene en los límites del estado de Pará o en las fronteras de Brasil, sino que alude a la sociedad global. En las últimas líneas de este texto ofreceré algunas interpretaciones sobre el proceso de patrimonialización internacional de la Amazonia, enfatizando el efecto de la globalización sobre las sociedades rurales y urbanas amazónicas. Para ello, el cañón se muestra como un vehículo narrativo de alta potencia por su doble naturaleza global: si por un lado funciona como una pieza clave en los debates contemporáneos que aquí trataremos, este cañón de posible origen europeo evoca también la huella colonial de la historia amazónica.

Y es que, aunque todavía no se ha realizado una datación científica de la pieza, es dable creer que el cañón fuera fundido a fines del siglo XVI o principios del siglo XVII, en el marco de las luchas europeas por el control del cauce amazónico (Ibáñez-Bonillo 2016). Hasta aquella época ni Castilla ni Portugal habían sido capaces de incorporar la desembocadura del río Amazonas a sus respectivos dominios imperiales, dejando abierta la región a las actividades económicas de sus principales rivales europeos. Uno de los ejes más activos de aquellos años se encontraba en el curso inferior del río Xingú, donde los holandeses habían levantado dos fortines para proteger sus intereses comerciales. Es posible que uno de ellos (Orange o Maturú) se encontrara en el lugar en el que hoy se alza la ciudad de Porto de Moz y hasta allí me dirigí en busca de sus posibles ruinas. Sin embargo, la ciudad actual no guarda ninguna memoria de esos tiempos, más allá del nombre de Maturú en uno de sus barrios. Decepcionado por esta amnesia total, mis esperanzas quedaron reducidas a un promontorio denominado Fortaleza que se encuentra en la orilla derecha del río Xingú, a unos diez kilómetros de la ciudad. Hasta allí me desplacé aprovechando la visita que debía realizar una delegación local del Partido de los Trabajadores (PT) a las comunidades de Maripí y Tauerá. No eran muchas mis expectativas en aquel viaje, pero cuál fue nuestra sorpresa al descubrir junto a un desembarcadero lo que parecía ser el cuerpo rugoso de un cañón. Era evidente que alguien lo había encontrado antes y lo había dejado allá, junto a la orilla, de manera intencionada. Preso de una súbita excitación, pedí a los chicos de la comunidad que me ayudaran a sacar aquel pedazo de hierro, que entre todos hicimos subir a la superficie.

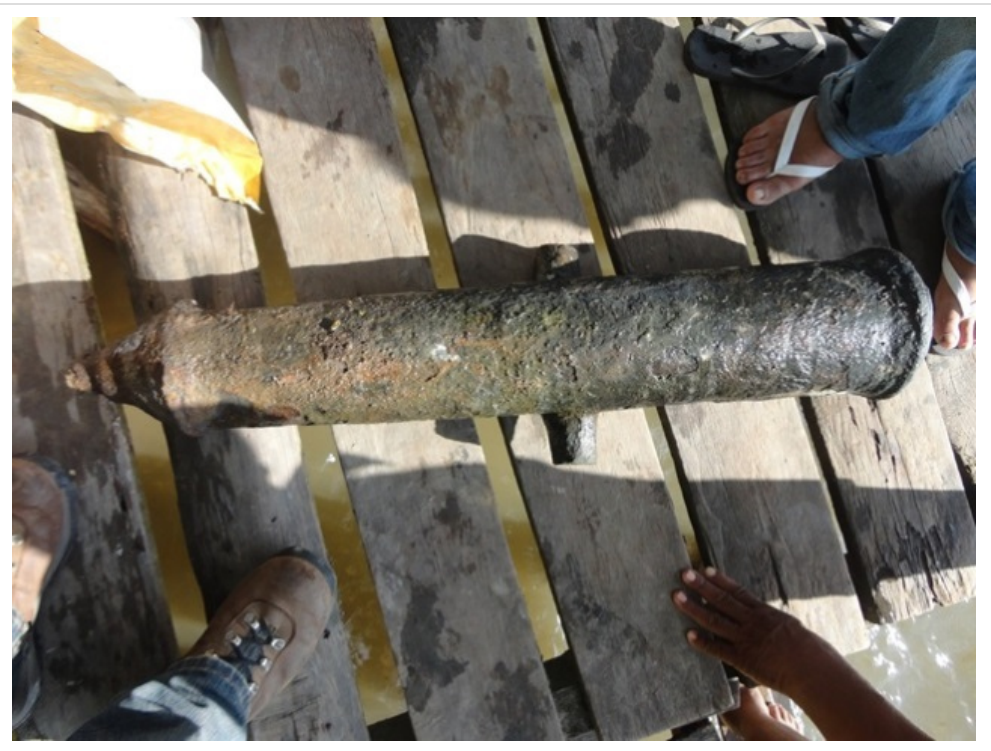

Fotografía: Pablo Ibáñez-Bonillo (2013)

Efectivamente se trataba de un cañón, corroído por el tiempo y la herrumbre, de un metro de longitud y sin señales ni escudos reconocibles. Por la simpleza de sus formas, tanto podría decirse que pertenecía al tiempo de la conquista portuguesa como a cualquiera de los conflictos posteriores que allí se habían desarrollado, especialmente la Cabanagem (Harris 2010). Resultó que tres mujeres lo habían encontrado en una playa cercana durante la marea baja y que lo habían transportado hasta allí con la intención de utilizar el objeto como ancla o lastre para una de sus embarcaciones. En aquel momento, el cañón solo era valorado por su forma y considerable peso: no era más que un pedazo de hierro. Uno de mis acompañantes en aquel viaje era un militante del PT, al que en este artículo llamaré Francisco. Consciente del interés que podía tener aquel cañón, él fue el primero en proponer que el objeto no podía quedarse allí en la orilla, expuesto a que las corrientes lo devolvieran al fondo del río. Intentamos subirlo a la comunidad, que se encontraba unos pocos metros más arriba, pero el peso de la pieza dificultaba nuestros movimientos. Ante aquella situación, Francisco habló con los presentes y les propuso trasladar 
el cañón en nuestra embarcación a la ciudad de Porto de Moz, donde estaría a buen recaudo para cuando ellos lo quisieran recuperar. Acordaron depositarlo en el local del Comité para el Desarrollo Sostenible (CDS), una agrupación de asociaciones locales que todos conocían. Ignorante de las relaciones invisibles que ataban a todos aquellos hombres e incapaz de prever la tormenta que se avecinaba, yo estuve de acuerdo con la decisión.

\section{El debate sobre la propiedad del cañón}

El traslado del cañón a Porto de Moz desencadenó una serie de reacciones por parte de los distintos actores municipales. Uno de los más interesados en el descubrimiento fue el Secretario municipal de Educación, quien veía en el cañón una gran oportunidad para la proyección del municipio. El político llevaba tiempo dándole vueltas a la necesidad de construir un museo local (la Casa de Cultura) y de articular un relato histórico coherente que hiciera justicia a los cinco siglos de historia de la ciudad. El cañón podía ser la cuña definitiva que desatrancase el proyecto y por eso se ofreció a albergarlo en las dependencias municipales a la espera de resolver la cuestión de su propiedad. Aunque nunca puso en duda que sus legítimos propietarios fueran los miembros de la comunidad en la que había aparecido, el Secretario municipal consideraba que todos los vecinos de Porto de Moz debían aprovecharse de aquel inesperado hallazgo. No solo en las dimensiones abstractas de la propia historia, sino también en los réditos económicos que pudiera generar, ya que el turismo es una industria floreciente en Porto de Moz y el reclamo de un nuevo cañón podría consolidar la oferta turística del municipio. Como muestra de su interés, el Secretario de Educación se ofreció a financiar un nuevo viaje con la esperanza de que yo encontrase más cañones en otras playas del río Xingú.

Ni Francisco ni el político lo explicitaron en sus conversaciones, pero lo que se discutía en aquellos momentos era quién debía ser el legítimo custodio del cañón. Francisco, que para entonces ya jugueteaba con sus propias hipótesis históricas sobre la existencia del fuerte y de barcos hundidos, proponía mandar aviso al Instituto de Patrimonio Histórico y Artístico Nacional (IPHAN), proyectando la importancia local del objeto a una escala nacional que se correspondía bien con su activismo político en el Partido de los Trabajadores y con sus luchas sindicales a lo largo y ancho del país. También el Secretario estaba de acuerdo con este paso, aunque se mostraba más práctico al tratar de resolver primero quién debía custodiar el cañón en las siguientes horas. Según su punto de vista, sería mejor trasladar el cañón desde el CDS a la Biblioteca Municipal. Sin embargo, y como si adivinaran el tipo de debate que se estaba llevando a cabo en la ciudad, la comunidad donde había aparecido el cañón envió a algunos de sus líderes al CDS para exigir la devolución de la pieza. No en vano, ellos ya tenían sus propios planes para patrimonializar aquel objeto; es decir, para construirlo socialmente a fin de que pudiera canalizar la representación de su colectividad (Valcuende 2003) (1).

Desde el año 2007 las comunidades de Maripí y Tauerá, junto a sus vecinas Taperú, Turú y Buiuçú, litigan para que el estado las reconozca como quilombolas o afrodescendientes. Para ellos este reconocimiento es tanto una cuestión de identidad cultural como de control de la tierra que vienen ocupando desde hace décadas y de la que dependen para su supervivencia, siendo la comercialización de farinha (harina de mandioca) y otros productos agrícolas su principal actividad económica. Desde el final de la dictadura militar (1964-1985) y la promulgación de la Constitución Federal de 1988 el estado brasileño viene ofreciendo varios itinerarios para que las comunidades campesinas regularicen su situación territorial. Dado que la mayoría de ellas han sufrido experiencias históricas de esclavitud, desarraigo y violencia, hoy en día la titulación de la tierra sigue siendo un problema pendiente y muchas comunidades no tienen ningún título de propiedad que las acredite como dueñas de las tierras que ocupan. Eso las coloca en una situación de riesgo a medida que la Amazonía se abre a la llegada de inversores y migrantes que compiten por estas tierras sin dueño legal. La lucha por la tierra en la Amazonía brasileña, y concretamente en el estado de Pará, es una de las historias más trágicas de los últimos años, contando ya en su saldo con centenares de muertos y amenazados en un pulso violento y desigual por el control de los recursos de la región. Es por esta permanente amenaza que las comunidades rurales han intentado regularizar su situación en los últimos años a través de los distintos mecanismos que el Estado pone a su alcance. 


\section{Mecanismos de acceso comunitario a la tierra}

Las Unidades de Conservación (UC) han sido una de las soluciones más populares en el marco amazónico. Aunque en realidad consisten en delimitaciones territoriales para la preservación del medio ambiente, las sociedades rurales amazónicas se han amparado en esta figura para regularizar su situación territorial y proteger sus intereses inmediatos ante las presiones de los invasores. Existen dos tipos de UC: las unidades de protección integral (UPI) y las unidades de uso sostenible (UUS). En las primeras no está permitida la presencia de comunidades, por lo que no merecen nuestra atención en este artículo. Las UUS, en cambio, sí consideran la permanencia de las sociedades tradicionales que al momento de la delimitación puedan demostrar la ocupación histórica de esos territorios. Eso sí, su permanencia está condicionada al cumplimiento de una exigente normativa ambiental y a la renuncia a cualquier título de propiedad sobre las tierras, las cuales pasan a ser de propiedad federal y son cedidas en usufructo a las comunidades. Existen varias modalidades de UUS, siendo las Reservas Extractivistas (RESEX) las más habituales y contándose en la actualidad 90 reservas que cubren casi $150.000 \mathrm{~km}^{2}$ del territorio nacional (2). La historia de este tipo de reservas se remonta a finales de la década de los 80 , cuando los seringueiros brasileños se movilizaron para obtener una figura jurídica que garantizase la continuidad de su modo de vida y de su entorno de una manera similar a como lo hacían los Territorios Indígenas ( $\mathrm{TI}$ ); para ello establecieron una alianza táctica con otros actores regionales (Aliança dos Povos da Floresta) y se alinearon con las tesis conservacionistas expresadas por ciertas ONG, facilitando la creación de las RESEX (Carneiro da Cunha y de Almeida 2000).

La RESEX más grande de Brasil se encuentra, precisamente, en el municipio de Porto de Moz. Se trata de la RESEX Verde para Sempre, creada en el año 2004 en la orilla izquierda del río Xingú después de una intensa campaña de presiones a escala regional que coordinaron las distintas asociaciones locales junto a grandes ONG internacionales como Greenpeace o WWF. La complementariedad de las agendas ambientalistas y locales ha sido una constante en las últimas décadas y ha permitido la consolidación de un frente común que defiende tanto la naturaleza como el mantenimiento de un modo de vida tradicional por parte de las comunidades rurales amazónicas frente a los intereses económicos de las grandes madereras, los gobiernos locales y el resto de actores de ambición desarrollista. El nacimiento de Verde para Sempre como fruto de esta colaboración permitió la delimitación de más de 1 millón de hectáreas (aproximadamente el $74 \%$ del territorio municipal de Porto de Moz) para su conservación sostenible, al tiempo que se permitía la permanencia de unas 2.600 familias en el interior de la RESEX. Desde el primer momento, la creación de la reserva fue experimentada como un triunfo colosal por parte de las comunidades locales, aunque con el paso de los años algunas familias han ido experimentando un cierto desencanto que también se puede percibir en otras RESEX brasileñas. Si en el corto plazo las Unidades de Conservación garantizaron la supervivencia de las familias al atajar las invasiones de tierra por parte de ganaderos y madereros, la ausencia de las inversiones federales comprometidas y el desconocimiento previo de las limitaciones a la actividad económica han terminado por dificultar el día a día en muchas de esas comunidades, tal y como he podido observar en distintas reservas.

La dimensión ambiental se encuentra presente también en otros mecanismos habituales en la Amazonia. Es el caso de los Proyectos de Asentamientos (PA) de la Reforma Agraria brasileña, dirigida por el Instituto Nacional de Colonización y Reforma Agraria (INCRA), a los que se han añadido algunos matices para conciliar los derechos territoriales de las sociedades rurales con la preservación del medio ambiente. Así han surgido modalidades como los Proyectos de Asentamientos Agro-Extractivistas (PAE), Proyectos Estaduales de Asentamientos Agro-Extractivistas (PEAEX), Proyectos de Asentamientos Florestales (PAF) o Proyectos de Desarrollo Sostenible (PDS), entre otros. Cada uno de estos PA debe contar con un Plan de Desarrollo del Asentamiento (PDA) negociado entre las autoridades y las familias beneficiadas (Pacheco 2009: 16-17). En estos planes deben recogerse las limitaciones ambientales específicas para cada uno de los asentamientos, aunque en realidad el cumplimiento de la legislación no es muy estricto y menos del 10\% de los 7.000 asentamientos que en 2006 había en el Brasil contaba con la licencia ambiental obligatoria, incumpliéndose permanentemente los límites acordados $\underline{(3)}$.

La presión conservacionista es menor en otras fórmulas que priorizan cuestiones etno-raciales, como los Territórios Quilombolas para poblaciones afrodescendientes, que en el estado de Pará asumen la forma de Territórios Estaduais Quilombolas (TEQ). A diferencia de las reservas extractivistas, el gobierno reconoce la propiedad (comunitaria) de la tierra en las TEQ y no establece medidas adicionales para la protección del medio ambiente, facilitando además el acceso a líneas específicas de financiación, como 
el programa Brasil Quilombola. Como en el caso de las RESEX, la figura jurídica de las TEQ apareció a finales de la década de los 80 aprovechando un contexto favorable para la regulación territorial de las sociedades agrarias en Brasil. Aunque en un primer momento los legisladores pensaron que esta solución jurídica tendría poco recorrido, la "resemantización" del término quilombo -ya no entendido como vestigio de las comunidades históricas de esclavos cimarrones, sino como una comunidad rural que se reconoce afrodescendiente (Arruti 2008)- ha popularizado de una manera extraordinaria la solicitud de TEQ en el país. La demanda ha sido especialmente intensa en los estados de Maranhão y Pará, donde hay una bien documentada historia de esclavitud de origen africano. En estos dos estados se han concentrado la mayoría de las solicitudes de los últimos años, situación que tanto se debe al gran volumen de poblaciones rurales sin titulación de la tierra como a la existencia de unas instituciones estatales favorables a las reivindicaciones de los afrodescendientes (De la Torre 2013).

Este clima propicio al reconocimiento de derechos especiales para las comunidades afrodescendientes no es exclusivo del caso brasileño y debe situarse en el marco más amplio del activismo etno-racial en otros países latinoamericanos, como Colombia o Ecuador. En ambos países se han ejecutado acciones afirmativas (Mosquera y León 2009) en pos de garantizar la inclusión de grupos históricamente subalternizados por su condición de afrodescendientes. Entre estas políticas públicas se incluyen también nuevas modalidades de acceso a la tierra que han provocado profundas redefiniciones identitarias entre los potenciales beneficiarios (Hoffman 2000). Muchas comunidades han invertido un considerable esfuerzo en actualizar su identidad étnica y sus prácticas culturales para cumplir con las expectativas de la legislación, en un juego cultural que tanto tiene de movimiento estratégico en lo material como de afirmación identitaria en lo simbólico (Wade 1999). Las actualizaciones culturales derivadas de estos cambios legislativos alteran en todos los casos las relaciones anteriores de autoridad y poder, desatando una serie de conflictos tanto al interior de las comunidades como en las relaciones de estas con sus vecinos, cuyas aspiraciones pueden ser contradictorias.

\section{El cañón y los quilombolas de Porto de Moz}

En este contexto de actualizaciones étnicas y tensiones comunitarias deben entenderse las reivindicaciones de las comunidades de Taperú, Turú, Buiuçú, Tauerá y Maripí, que en el año 2007 constituyeron la Asociación de Remanescentes Quilombolas del Bajo Xingú. Aquel fue el primer paso en una larga batalla contra los intereses de otros actores locales que ya habían asistido con espanto a la pérdida del $74 \%$ del territorio municipal con la creación de la RESEX Verde para Sempre y que ahora temían perder su influencia también sobre las tierras que los quilombolas reivindicaban para sí. Hay que tener presente que Porto de Moz fue hasta principios del siglo XXI un coto privado de explotación maderera para un puñado de familias locales, así como para su corte de clientes y aliados, la cual se proyecta en medios de comunicación (Radio Porto FM) y en partidos políticos. Junto a estos actores, y según fui descubriendo durante mis entrevistas, también se posicionaron en contra de los quilombolas otras familias que habían ocupado o comprado lotes de tierra en el pasado y que ahora temían ser expropiados y perder su inversión.

En el momento del descubrimiento del cañón yo no sabía que uno de esos propietarios podía ser el mismo Francisco que me acompañaba. Solo en los días posteriores creía averiguar que muchos años atrás Francisco había comprado unas tierras y que la propiedad de esos lotes era puesta en cuestión por el reclamo de los quilombolas. Eso le hacía dudar del proyecto quilomba, en una duda que se veía reforzada por su disciplina de partido. $Y$ es que el Partido de los Trabajadores, que tradicionalmente se había posicionado a favor de causas semejantes, venía virando en los últimos años hacia posiciones más desarrollistas que chocaban con la tupida red de los movimientos sociales de Porto de Moz. La evolución definitiva del PT se había evidenciado recientemente a raíz de la construcción de la presa hidroeléctrica de Belo Monte sobre el río Xingú, una cuestión ambiental de enorme importancia regional y nacional en la que el partido de Lula y Dilma Rousseff se había comprometido especialmente. La defensa de la construcción de la presa por parte de los militantes y regidores del PT había sido la muestra definitiva de la nueva agenda que el partido venía adquiriendo en la Amazonía, una agenda distinta a la de los quilombolas y sus aliados. Tal y como me declaró un líder local del PT, los quilombolas reclamaban un territorio demasiado grande y de una manera demasiado ambigua.

Entre los aliados de los quilombolas, por otra parte, destacaban especialmente la parroquia local, 
controlada por el muy progresista obispado del Xingú, y el Sindicato de los Trabajadores Rurales (STTR), dos fuerzas de una enorme influencia regional que también se inscriben, como el PT, en tendencias mucho más profundas, de alcance nacional. Así, por ejemplo, la labor del obispado del Xingú en la conformación de las Comunidades Eclesiásticas de Base (CEB) y en el acompañamiento de sus luchas sociales en las últimas décadas no puede disociarse de la corriente de la Teología de la Liberación ni de los efectos del Concilio Vaticano II y de la Conferencia de Obispos en Medellín de 1968, acontecimientos que ayudaron a canalizar una corriente de pensamiento crítico dentro de la iglesia brasileña, dando origen a la Comisión Pastoral de la Tierra (CPT). Erwin Krautler, obispo del Xingú desde 1980 tras suceder a su tío Eurico Krautler, se ha convertido en una figura pública de gran trascendencia gracias a su liderazgo en campañas en favor de las comunidades más desfavorecidas de su obispado, lo que le ha valido múltiples amenazas de muerte. Por su parte, el STTR tiene también una larga trayectoria dentro del sindicalismo comunitario que ha permitido la emancipación de los trabajadores rurales sometidos históricamente a las dominaciones de patrones y coroneles primero, y de ganaderos y terratenientes después. La labor del STTR debe enmarcarse en las luchas compartidas con otros movimientos nacionales de corte similar como la Central Única de Trabajadores (CUT) o el Movimiento de los Trabajadores Sin Tierra (MST).

Tanto la parroquia local como el STTR han sido actores centrales en los movimientos sociales de Porto de Moz (Moreira 2008) y actuaban en 2013 como los principales valedores de los quilombolas del Bajo Xingú. Por eso respaldaron su decisión de acudir al Comité de Desarrollo Sostenible a exigir la devolución del cañón. Aquel pedazo de hierro que horas antes apenas sí tenía valor, comenzaba ya a cargarse de significados mucho más profundos y visibles. Tuve la oportunidad en aquellos días de entrevistar a uno de los responsables de la comunidad quilombola, quien pudo confirmarme aquel cambio de valoración. Al enterarse de la aparición del cañón, según me contó, los mayores de la comunidad habían reaccionado con el mismo temor con el que solían recibir los hallazgos de otros objetos antiguos. Ya no era solo indiferencia ante un pedazo de hierro, sino la intuición de que aquel objeto podía traer desgracias a la comunidad. Los jóvenes, sin embargo, más formados y por ello mismo responsables del liderazgo externo de las comunidades, opinaban de una manera diferente. Aquel cañón no solo no iba a suponer un problema, sino que debía ser recibido como un regalo o un don del pasado, una prueba adicional en su reivindicación colectiva por el derecho a la tierra. Y por eso mismo habían acudido tan pronto al CDS para exigir su devolución.

La lectura que los jóvenes quilombolas hicieron del cañón es sumamente interesante y debe interpretarse como parte del proceso de reinvención y recreación de su identidad colectiva, un esfuerzo por recuperar elementos culturales del pasado que faciliten la cohesión actual del grupo y el reconocimiento externo de su identidad afrodescendiente. En esa línea, tal y como ha venido ocurriendo en muchas otras comunidades quilombolas del país, los miembros más jóvenes de la comunidad han realizado una apuesta clara por enfatizar determinadas expresiones culturales asociadas a cierta idea de "africanidad", como la práctica de capoeira, el consumo de gengibirra (mezcla de cerveza, cachaça y jengibre) o la ejecución de danzas y géneros musicales como gambá o carimbó. Junto a estas prácticas, resulta habitual también la reconciliación con y apropiación de patrimonios monumentales y objetos antiguos. Tal y como pude recoger en mis entrevistas con los miembros de las cinco comunidades, hoy existe una mayor conciencia de la importancia de la conservación de estos objetos (ya sea cerámica indígena o botellas antiguas), que son guardados en colecciones particulares a la espera de habilitar un espacio comunitario permanente para dicho fin. Estas piezas son interpretadas por las nuevas generaciones como un patrimonio histórico que legítimamente les pertenece y que refuerza su vinculación con la tierra que ahora reclaman, una materialización de su identidad y de "su proceso de construcción y vivencia colectiva" (Hernández y Ruiz 2011: 175).

Esta apropiación del pasado permite la cohesión del grupo, pero también contribuye a modelar la jerarquización interna de las comunidades. Son los nuevos líderes, asesorados desde fuera, quienes definen los límites del patrimonio y "educan" a los demás. Estos jóvenes líderes, formados en las ciudades, ven aumentado su prestigio social por la capacidad que tienen para valorar en su justa medida (según el criterio externo) el patrimonio colectivo, accediendo a una posición de privilegio que permite legitimar su liderazgo, puesto en duda muchas veces desde el interior de la comunidad por su propia juventud, inexperiencia o exposición a las corrientes citadinas. En ese sentido, el patrimonio es siempre una herramienta al servicio de las élites instruidas que son capaces de apropiarse del capital simbólico que un cañón o un yacimiento puedan albergar (Quintero 2009: 44). Esta visión del patrimonio como un 
arma en la definición de las luchas sociales o como un espacio de conflicto entre distintos actores, teorizada en los últimos años por autores como Néstor García Canclini o Francisco Cruces, será la que guíe mis interpretaciones sobre el hallazgo del cañón en el presente artículo.

Por otra parte, este proceso de patrimonialización de las costumbres y los objetos no se dirige solamente hacia el interior del grupo en su búsqueda de definir una identidad cohesionada o una nueva jerarquía social, sino que se proyecta también hacia el exterior buscando el reconocimiento ajeno. Para unas comunidades que tan injusta como habitualmente son acusadas de carecer de historia propia y de sólidos fundamentos para sus reivindicaciones identitarias, elementos como el cañón suponen un argumento de peso en su comunicación con el resto de grupos del municipio y del estado. Siendo tan importante la cuestión del reconocimiento positivo en el desarrollo de las minorías culturales (Taylor 1993), estos procesos de apropiación y resignificación se nos aparecen como totalmente comprensibles. No hay nada reprobable en ellos aunque sí abren la puerta a dos discusiones de trascendencia. La primera está relacionada de nuevo con la propiedad del cañón, puesto que la apropiación del mismo por parte de las cinco comunidades quilombolas implica la exclusión del resto de habitantes municipales de un objeto susceptible de haber recorrido otros procesos de patrimonialización. En un entorno tan polarizado y violento como resulta la Amazonia paraense, es sencillo comprender el celo de los quilombolas y de sus aliados por proteger ese bien, pero quizás en el futuro se planteen otras posibilidades que permitan reconciliar sus aspiraciones con los procesos etnogenéticos de otras comunidades urbanas o ribeirinhas que comparten el espacio municipal.

La segunda discusión tiene que ver con el tipo de relato histórico que las comunidades amazónicas construyen para cimentar sus identidades y sus reivindicaciones territoriales. Los líderes quilombolas a los que pude entrevistar tenían una conciencia clara de que el cañón pertenecía a un tiempo anterior al de su comunidad actual, formada en la primera mitad del siglo XX. Sin embargo, otras voces que pude recoger en aquellos días tendían a elaborar un relato en el que se superponían todos los tiempos y los objetos. Al descubrir el cañón yo había planteado la posibilidad de que este perteneciera al tiempo de los holandeses y del fuerte de Maturú, lo cual significaría una antigüedad de 400 años que todavía no ha sido posible verificar. Según mi hipótesis, tal y como comenté aquellos días, el cañón habría sido contemporáneo de los esclavos de Angola que los holandeses tenían en el fuerte al momento de la conquista portuguesa en 1623. Este dato, desconocido hasta entonces, pronto se filtró en las interpretaciones locales y estaba ya a plena vista en el relato que algunas personas compartían pocos días después, un relato en el que los esclavos angoleños aparecían como los cargadores del cañón en un pasado brumoso en el que se confundían las figuras de los holandeses (siglo XVII), los cabanos (1835-1840) y el empresario cauchero José Julio de Andrade (1899-1948).

En ese sentido, vale la pena señalar que en la mentalidad de las comunidades ribeirinhas que conocí en el Bajo Amazonas el tiempo histórico parece dividirse en tres épocas que funcionan como hitos temporales con los que organizar los distintos objetos que se van encontrando en el subsuelo o en el fondo del río. El tiempo de los indios es el más antiguo de todos y sus vestigios son tratados con una mezcla de miedo y respeto, pues generalmente se asume que sus antiguos propietarios fueron los primeros habitantes de este lugar y que algún día podrían regresar a buscar sus vasijas o las caretas antropomorfas que proliferan en los depósitos de tierra negra. La relación con los indígenas y su pasado, de todas maneras, depende mucho del discurso al que las comunidades hayan sido expuestas en los últimos años, siendo más amables las visiones influidas por los movimientos de izquierdas y la teología de la liberación. Sorprendentemente, el tiempo de la conquista europea y del periodo colonial acostumbra a estar ausente de la tradición oral ribeirinha, que pasa de puntillas por la ocupación portuguesa y se explaya en el tiempo de los cabanos decimonónicos, representados en las historias como rebeldes contra la causa de un Brasil unido, salvajes que trajeron el caos y la muerte a los igarapés (4). Las historias de cabanos hacen alusión a tesoros, saqueos, violaciones y rupturas traumáticas. El tercer tiempo histórico que ordena la tradición oral es el tiempo del patrón, la seringa y la castaña, en el que ya se insertan las comunidades actuales, reconociendo a sus ancestros (de hasta dos o tres generaciones) como participantes de dicho periodo.

\section{Un cañón no tan quilombola}

El cañón, debido en parte a mis suposiciones cronológicas, encontraba difícil acomodo en ese esquema 
histórico. Podríamos decir que pertenecía al inclasificable "tiempo de los antiguos". El cañón, según ese punto de vista, podía ser más viejo o más nuevo que el tiempo de los indios o que el tiempo de los cabanos; o incluso pertenecer a uno de esos dos tiempos. También podría haber pertenecido al coronel Zé Júlio, aseguraban algunos. A pesar de esta indefinición (o quizás gracias a ella), el cañón se convirtió en cuestión de horas en un objeto preciado para todos los actores. El día siguiente se celebró un simposio informativo sobre el proyecto quilombola en la comunidad de Taperú al que asistieron representantes del campus de Altamira de la Universidade Federal de Pará (UFPA), así como otros investigadores y autoridades. El evento estaba organizado desde mucho antes pero sirvió también para presentar en sociedad al reemergido cañón, el cual fue situado en el centro del salón comunitario, presidiendo de manera simbólica los distintos eventos que se desarrollaron aquel día. Fui invitado a participar del seminario, pero no pude llegar a tiempo porque Francisco me propuso un desvío. Aquella propuesta de Francisco, de quien dependía enteramente para mi movilidad fluvial, acabó por revelarme una de las aristas más interesantes de esta "situación social".

El nombre original con el que se constituyó la asociación quilombola del Bajo Xingú es "Associação das Comunidades Remanescentes de Quilombola Tauerá, Buiuçu, Taperu e Turu e Parte de Moradores do Maripi". El interés aquí se encuentra en esa fragmentación de la comunidad de Maripí, representada únicamente por una parte de sus habitantes en la asociación quilombola. Y eso es precisamente lo que Francisco quería mostrarme: que no todas las familias compartían el proyecto político e identitario de los quilombolas. Según datos del Instituto de Terras do Pará (ITERPA), el número de familias que se autodefinían como quilombolas había bajado considerablemente desde el registro de la asociación en el año 2007 (5). Desde entonces las cinco comunidades habían sufrido fuertes presiones por parte de los políticos locales, madereros y particulares que estaban en contra del proceso de titulación de tierras, los cuales no habían descansado en sus campañas por insuflar miedo y reticencias en algunas de las familias locales. Los opositores al reconocimiento de los quilombolas trataron de sembrar la semilla de la división entre los afrodescendientes y aquella semilla había encontrado acomodo en algunas familias de Maripí que, más allá de los incentivos externos, tenían sus propias razones para rechazar el nuevo proyecto y buscar la alianza de intermediarios locales.

Mientras en Taperú se realizaba el seminario después del hallazgo del cañón, con la participación del párroco local, del prefecto y de otras autoridades municipales, yo tuve la oportunidad de entrevistar a miembros de algunas familias disidentes, las cuales se quejaban (quizás hipócritamente) de no haber sido invitadas al evento. En realidad, la invitación tampoco hubiera servido de nada porque ellos ya tenían muy bien definida su posición. Estaban en contra de la reivindicación quilombola, de hecho estaban en contra de la propia palabra quilombola, que pronunciaban de manera grotesca y burlona ("carambola", por ejemplo) para mostrar todo su desprecio, tal y como ya había escuchado que ocurría en la ciudad. Sus argumentos para estar en contra eran muchos y de signo variado. El más evidente de todos ellos tenía que ver con la falta de voluntad para vincularse a una identidad débil y traumática que automáticamente les retraía a los tiempos de la esclavitud. Nosotros no queremos ser esclavos, decían. Y en su convicción había una fuerte determinación por impedir esa vinculación con un pasado de violencia y cautividad. No era solo que se negasen a volver al tiempo de la esclavitud, sino que algunos de ellos incluso negaban el haber atravesado esa experiencia histórica. Y más todavía: supe de un hombre de evidente ascendencia afrobrasileña que afirmaba ser blanco y que nadie le haría creer que él era negro o descendiente de esclavos.

Su actitud resoluta respecto a aquel tema se proyectaba también hacia una anciana, cuyo testimonio era especialmente precioso por la nitidez de sus recuerdos sobre las costumbres de sus antepasados. Los oponentes locales a la causa quilombola habían identificado esos recuerdos de la anciana como una grieta por la que se filtraba su verdadera herencia afrodescendiente y en un último intento por detener la filtración le habían prohibido a aquella mujer, que en la época tenía 95 años, recordar las cosas del pasado y, mucho menos, contarlas a desconocidos. Tampoco les parecía una buena idea realizar trabajos arqueológicos en su comunidad. Se trataba de un esfuerzo de olvido colectivo muy similar al que he podido observar en otras comunidades ribeirinhas de la región respecto a las viejas historias animistas sobre los espíritus, la metamorfosis de los cuerpos, los encantados que viven en el fondo del río o las actividades de los pajés de bancada o hechiceros locales. En ambos casos se ejerce una presión colectiva sobre los ancianos para obtener su silencio cómplice y hacer morir con ellos el recuerdo de unos tiempos que se quieren silenciar. Si el patrimonio sirve para proyectar la imagen que nos gustaría tener de nosotros mismos, el olvido y el silencio pueden jugar por omisión una función similar. 
Esta sucesión de negaciones puede ser interpretada fácilmente desde la experiencia histórica de la violencia sufrida así como del racismo todavía latente en la sociedad brasileña. Esta herida colectiva bastaría para entender las preferencias identitarias de estas familias, pero es imposible realizar un análisis social en la Amazonia paraense sin tener en cuenta el factor transversal que atraviesa todas las discusiones comunitarias: el control de la tierra. Como se ha dicho más arriba, la propiedad y el uso de la tierra son aspectos fundamentales en esta región, habitada por comunidades que han vivido siempre en la ocupación alegal de unos territorios sin dueño reconocido en los que encontraron acomodo al margen de las grandes explotaciones caucheras o ganaderas. La experiencia de estas y de muchas otras comunidades ribeirinhas con relación a la tierra consiste en una ocupación temporal, sin reconocimiento legal definitivo, amenazada siempre por factores humanos y ambientales, que solo por costumbre e insistencia se ha ido convirtiendo en permanente. En estas tierras sin titulaciones, el acuerdo consuetudinario rige el reparto de los espacios productivos, siendo muy frecuentes los choques y rivalidades entre familias por el control de determinados pedazos de tierra. La pugna por el control del suelo agrícola o de los mejores pastos se solapa de manera inevitable con los posicionamientos políticos y con los procesos de redefinición identitaria.

Y así ocurría también en la comunidad de Maripí. Las familias a las que entrevisté mostraban abiertamente su temor a que la titulación colectiva de las tierras les perjudicase en sus actividades económicas habituales. Por un lado tenían miedo a las posibles limitaciones y sanciones económicas que el Instituto Brasileiro do Meio Ambiente e dos Recursos Naturais Renováveis (IBAMA) pudiera infligirles, a semejanza de lo que ocurría en la vecina RESEX Verde para Sempre. Este temor se veía sustentado en una serie de rumores que circulaban por la región y que remitían al desencanto que hoy sentían los habitantes de la RESEX. Por otro lado, las personas a las que entrevisté estaban seguras de que la titulación colectiva de la tierra les arrebataría el control de las parcelas que en los últimos años venían explotando. Era este un temor que compartían con otras familias que se habían asentado en los últimos tiempos en zonas que ahora reclamaban los quilombolas como parte de su territorio tradicional. Estas familias de migrantes temían verse obligados a abandonar el lugar e incluso aseguraban que los quilombolas ya estaban ocupando "sus" tierras.

Los recelos de estas familias no pasaron desapercibidos al resto de interesados en la paralización del proceso quilombola. Actores intermediarios habían ejercido de correa de transmisión entre esas familias y los intereses políticos y económicos que estaban en juego, los cuales eran representados en Porto de Moz por un puñado de familias influyentes y por determinados partidos políticos. Entre todos ellos se había forjado una alianza táctica y tácita que tenía por objetivo demorar al máximo, e incluso suspender, el proceso de reconocimiento a los quilombolas por parte de las autoridades estatales. A pesar de contar con los argumentos jurídicos suficientes, y en concordancia con la lentitud general en la resolución de los expedientes durante los últimos años, el caso de los quilombolas del Bajo Xingú no se ha desencallado todavía desde el año 2007. Es posible que las presiones de las altas esferas locales hayan contribuido a esta paralización.

Un ejemplo de la alianza táctica anti-quilombola ocurrió algunas semanas después del hallazgo del cañón, cuando el 8 de julio de 2013 los regidores (vereadores) municipales elevaron una carta al ITERPA solicitando la paralización de "cualquier acción que conmine con creaciones de 01 TEQ (Território Estadual Quilombola) y 01 PEAX (Projeto de Assentamento Estadual Agroextrativista) (...) por considerar que esta modalidad no expresa la voluntad de la mayoría absoluta de los moradores que viven hace años en estas áreas, algunos con más de 80 años, que siempre soñaron en tener sus títulos definitivos individuales". En la carta se hace referencia a la ausencia de "comprobación antropológica de la existencia de remanescentes de quilombos", argumento que hace eco del amplio debate existente a nivel nacional sobre el sentido original del término quilombo y las características necesarias para ser reconocido jurídicamente como tal. Aunque la legislación favorece el auto-reconocimiento, existe una "verdadera batalla parlamentaria y jurídica que se acaba manifestando en el campo social por medio de la organización de manifestaciones contrarias a la regularización de las tierras quilombolas en la prensa mayoritaria". La queja de los regidores no era en este sentido un exabrupto meramente local, sino que entroncaba con las habituales "acusaciones graves y violentas de falsificación identitaria por parte de las comunidades quilombolas y del INCRA" (Arruti 2008: 335). De todos modos, el problema no estaba tanto en la identidad ni en la historia, sino en el control de la tierra. Por eso expresaban en la misma carta que "en reunión con técnico del ITERPA, fue constatado en votación con los moradores, donde la gran mayoría optó por la modalidad de PEAS (Projeto Estadual de Assentamento Sustentavel) y por la 
regulación fundiaria individual" $\underline{6}$.

\section{Un cañón en la Amazonia global}

Esta misiva, que estaba firmada por el presidente de la Cámara, dos secretarios y diez regidores, da la medida de la batalla global en la que se han visto inmersas las comunidades rurales del Bajo Xingú. Son en realidad dos modelos de gestión de la tierra en la Amazonía los que están en pugna en esta región, dos concepciones generales que responden a intereses internacionales y a luchas partidarias dentro del escenario político brasileño, y que las comunidades locales aprovechan en beneficio propio para negociar sus aspiraciones inmediatas (individuales y grupales) a través de los intermediarios disponibles. Así, la carta de los regidores de Porto de Moz aboga claramente por la titulación individual de la tierra, recogiendo un viejo anhelo de las familias ribeirinhas, muchas de las cuales han experimentado una historia de aislamiento e individualismo extremo en las estradas del caucho o en las orillas de los ríos durante el siglo XX. Este reconocimiento de la propiedad privada encaja bien con los anhelos de una parte de la población municipal (sobre todo la urbana) y mucho mejor todavía con las necesidades de los empresarios y comerciantes que dependen de los recursos naturales de la región. En la Amazonia del siglo XXI no son pocos los que desean engancharse al libre mercado y a las ventajas de un sistema capitalista que funciona en el resto del país y que conocen a través de la escuela y de los medios de comunicación. Es una aspiración compartida incluso por una parte de los movimientos de izquierdas, para los que el progreso y la dinamización de la economía no pueden lograrse solo a través de la perpetuación de un modo de vida tradicional.

En la otra cara de la moneda, los proyectos que aspiran a un reconocimiento colectivo de la tierra espejan a su vez una determinada visión del desarrollo amazónico que fue definida y trabajada a partir de la segunda mitad del siglo XX por determinados sectores de la iglesia, sindicatos, partidos políticos de izquierdas y ONG internacionales. Los discursos ambientalistas y comunitarios, inspirados parcialmente en las culturas indígenas y en la tradición misional, fueron incorporados tardíamente por la mayoría de comunidades ribeirinhas, históricamente golpeadas por las exigencias de los mercados internacionales. Si algo definió al cauchero histórico, como escribiera el escritor brasileño Euclides da Cunha en la mítica À margem da história (1909), eran el aislamiento y el sometimiento a la figura del patrón. Y también la práctica de un ambientalismo de supervivencia, mediado por espíritus protectores de la naturaleza, que no estaba acompañado de ningún discurso conservacionista. No sería hasta el agotamiento de los últimos ciclos extractivos y la desaparición de los patrones del caucho cuando una cierta visión utópica de las sociedades tradicionales amazónicas (colectivista y conservacionista) pudo extenderse por la región. El éxito de esta visión se debió en parte a las dinámicas sociales pre-existentes, pero también al hecho de que las sociedades locales vieron en ella una herramienta útil para asegurar el control de la tierra en el corto plazo.

La Amazonia, por tanto, está atravesada por distintos discursos y aspiraciones que entran en contradicción y que remiten a dos visiones opuestas del desarrollo. Estos antagonismos tomaron cuerpo ante mis ojos a partir de la aparición del cañón, el cual seguía siendo celebrado en el centro del salón comunitario de Taperú mientras yo recogía los testimonios en Maripí. La reacción de los entrevistados en Maripí ante la noticia del descubrimiento del cañón era espontánea y unánime: lo primero que había que hacer era averiguar dónde había aparecido el cañón exactamente y después ver a quién pertenecía en realidad. Porque si había aparecido en Maripí no se entendía que "los de Taperú" lo hubieran ido a buscar al Comité. No les parecía bien, en definitiva, que se hubieran apropiado del cañón de malas maneras, violentando el espacio neutral que suponía el Comité para el Desarrollo Sostenible. Incluso llegaron a fanfarronear ante mí con la posibilidad de ir en aquel mismo instante a Taperú y recuperar el cañón a la fuerza. Ahora bien, ¿por qué el cañón era tan importante precisamente para aquella gente que se empeñaba en silenciar los recuerdos de los ancianos? Me preguntaron si el cañón era valioso y no supe bien qué responder. Obviamente, ellos no valoraban las historias que el objeto pudiera contar, sino que su voluntad era silenciar esas mismas historias, hacerlas desaparecer, callar las voces que les pudieran emparentar en un pasado común de esclavitud y oprobio con sus vecinos. El cañón se había convertido en una amenaza real para las familias de Maripí.

Y para los demás actores, ¿por qué era tan importante el cañón? Una mujer llegó a decirme que el cañón era una doble y definitiva prueba: de la existencia de Dios y del pasado esclavo de los quilombolas. 
¿Cómo era que aquel pedazo de hierro podía llegar a confirmar la existencia de Dios? La respuesta quizás pase por entender las causas que hicieron del cañón, a ojos de todos, un bien patrimonializable. Estos bienes, por lo general, deben cumplir tres características que se encontraban en el cañón: deben ser objetos excepcionales, escasos y poseedores de una considerable profundidad temporal. Estos rasgos confieren un aura mágica a determinados objetos que pasan a acaparar la atención de la comunidad y que se convierten en depositarios de los más variados significados (Quintero 2009, Cruces 1998). Además, en el caso concreto del cañón, se puede pensar en otros argumentos que reforzarían su excepcionalidad, como por ejemplo su carácter agresivo, bélico y por tanto transmisor de ciertos valores de resistencia y masculinidad que se ven aumentados por la forma fálica del mismo. Pero también su origen europeo o la naturaleza metálica, sólida e inquebrantable, de un objeto que alude a un determinado imaginario regional en el que son muy conocidos los cañones de Belém y Macapá y, por proximidad, también los del fuerte de Gurupá. En este sentido, el hecho de que los quilombolas situaran el origen histórico de su comunidad en Gurupá incrementaba el valor simbólico del cañón.

Acabadas mis entrevistas, Francisco me llevó al seminario de Taperú. Allí fui recibido por unas miradas de sospecha y reprobación que supongo tenían que ver con mi ausencia en las horas anteriores, con mi visita a los disidentes y también por aparecer acompañado de Francisco. Demasiados errores que pagué en los días siguientes con el vacío de los quilombolas y sus aliados. Llegué a tiempo de presenciar los últimos parlamentos y la ejecución de algunas danzas en el salón comunitario, donde el cañón seguía expuesto junto al resto de objetos antiguos rescatados por la comunidad en los años anteriores. El salón actuaba aquel día como un museo (7) del patrimonio local donde los objetos y las personas formaban parte de un mismo ritual mediante el cual se reforzaban los lazos que unían a los distintos miembros de la comunidad entre sí y con la tierra que ocupaban, así como con los que la habían ocupado antes de ellos, es decir, con el pasado y la historia del lugar. Aquella teatralización estaba dirigida a los participantes de la reunión, sí, pero también dialogaba con los representantes municipales y estatales que allí se encontraban, exigiendo un reconocimiento para la antigüedad que, puesta en escena, había sido ya reapropiada por la comunidad actual. Incluso se había decorado el cañón con cintas de colores para enfatizar el impacto estético que el objeto pudiera producir.

Fui consciente entonces de que el cañón ya se había convertido en algo mucho más importante para ellos de lo que pudiera ser para el joven historiador que yo era entonces, así que en los días posteriores recogí mi equipaje y continúe mi periplo por otras comunidades ribeirinhas asentadas sobre antiguos escenarios históricos de la época colonial temprana. No regresé a Porto de Moz hasta tres meses después, esperando encontrar los ánimos algo más calmados y ya con la convicción de moverme libremente por la ciudad y sus alrededores, evitando la problemática, aunque agradable, compañía de Francisco en la medida de lo posible. De nuevo volví a presentarme en la sede del CDS, del STTR y de la parroquia local. El recelo continuaba siendo manifiesto, pero creo que mis explicaciones sirvieron para generar compasión y los líderes quilombolas me autorizaron a pasar dos días con ellos entrevistando a algunos miembros de su comunidad.

Durante aquel segundo viaje a Porto de Moz me enteré del peculiar destino que había tenido el viejo cañón. Según me dijeron en la ciudad, un grupo de hombres de Maripí había ido finalmente hasta Taperú para recuperar el cañón. Es difícil saber si realmente pensaban regresar cargados con él o si simplemente querían escenificar de manera violenta su desacuerdo con la apropiación del mismo por parte de sus vecinos. Sea como fuere, su visita derivó en una pelea. Me fue imposible confirmar esta historia, pero, en cualquier caso, el cañón no se movió de Taperú. Ante la posibilidad real de que alguno de los múltiples enemigos que tiene la causa quilombola intentase apropiarse de aquel objeto, los líderes comunitarios decidieron guardar el cañón en un lugar seguro que solamente conocerían unas pocas personas. Yo no fui una de ellas, obviamente, y tampoco volví a ver de nuevo el poderoso artefacto en que se había convertido aquella reliquia histórica, que sigue hoy a orillas del Xingú a la espera de que sus significados sean actualizados y requeridos en el futuro $\underline{(8)}$.

Para entonces el cañón, en su calidad de patrimonio, volverá a ejercer el doble influjo que en su efímera presencia generó sobre las gentes de Porto de Moz. Un vecino de la ciudad especialmente emocionado con el hallazgo me confesó que el cañón era una revelación extraordinaria, una pieza que iba a estimularle a él y a otras personas a conocer mejor la historia del municipio. El cañón fue durante unos días un estímulo y un rayo de esperanza, una especie de fetiche o amuleto mágico que alimentó las esperanzas de varios grupos en el municipio. Fue un documento de barbarie (de la guerra europea) 
convertido en un documento de cultura. Pero al mismo tiempo también fue un objeto de disputa, una fuente de problemas, un arma peligrosa que unos y otros utilizaron para marcar los límites de su identidad colectiva y para excluir a sus rivales. $Y$ es que "los monumentos y museos son, con frecuencia, testimonios de la dominación más que de una apropiación justa y solidaria del espacio territorial y del tiempo histórico. Las marcas y los ritos que lo celebran hacen recordar aquella frase de Benjamin que dice que todo documento de cultura es siempre, de algún modo, un documento de barbarie" (García Canclini 1990: 179).

Esta doble naturaleza del patrimonio, como documento de barbarie y como documento de cultura, no es una característica exclusiva del patrimonio histórico material, sino que también es propia de otros bienes patrimoniales como puedan ser las tradiciones orales o las obras de arte. Y, por supuesto, el patrimonio ambiental. $Y$ como cierre de este artículo me gustaría tender un hilo invisible entre aquel cañón herrumbroso de Porto de Moz y la Amazonia como patrimonio natural de la humanidad, detectando la misma dualidad en los significados de ambos objetos mentales. El cañón nos ha hablado en este texto sobre las rivalidades locales por el control de la tierra y por la explotación de los recursos naturales, pero también nos ha contado algo sobre la política federal para el desarrollo de la región y sobre el papel de la iglesia y de los movimientos sociales en la Amazonia, dibujando en última instancia dos modelos posibles de gestión para el patrimonio amazónico, modelos que responden de manera distinta a las exigencias de los mercados internacionales y que conectan a la Amazonia con el sistema global y con cuestiones como el cambio climático y el futuro de la humanidad. Es finalmente en el debate global sobre el futuro de la Amazonia donde debe insertarse la brusca aparición (y la no menos brusca desaparición) de aquel cañón, ya que todas las reacciones locales, las identidades, las estrategias territoriales y los relatos identitarios solo pueden ser comprendidos a partir de su posición relativa en un sistema global (Friedman 2001) que percibe a la Amazonia como patrimonio de la humanidad. Se trata, en definitiva, de una negociación entre los actores locales y el mundo globalizado que propone modelos de desarrollo, tensa relación que tanto sirve para entender el triste destino de un cañón como para pensar el incierto futuro de la Amazonia en su conjunto.

\section{Notas}

1. Según Victoria Quintero, "el patrimonio está configurado por el conjunto de elementos que un colectivo social considera representativos de su identidad como tal" (Quintero 2009: 41). Estos elementos son dotados de significado a través de un proceso social. "La noción de patrimonio remite a una construcción de carácter político que dota de un refuerzo simbólico especial a determinados bienes (o actividades) que se dirigen a la consolidación de un 'nosotros' determinado" (Quintero 2009: 48). Se habla de patrimonialización para referir "el carácter dinámico, procesual y de construcción social que tiene el patrimonio, de interacción entre diferentes agentes que construyen y reconstruyen diversos significados" (Quintero 2009: 49).

2. Datos del Cadastro Nacional de Unidades de Conservação, actualizado en febrero de 2015. http://www.mma.gov.br/images/arquivo/80112/CNUC_Categoria_Fevereiro_2015.pdf (consultado el 05/04/2016).

3. Araújo, F. C. Reforma agrária e gestão ambiental: encontros e desencontros, UNB/CDS. Brasília/D.F., 2006 (citado en Pacheco 2009: 17). La cifra actual de asentamientos es de 9.256 (http://www.incra.gov.br lassentamento).

4. Se trata de una visión muy conservadora del proceso histórico y deudora de una historiografía puesta al servicio de los vencedores del conflicto. Esta visión tan negativa parece no reproducirse en otros lugares que no he visitado, como en determinadas zonas del bajo Tapajós que actuaron como centro de resistencia de la Cabanagem.

5. "Defensoria realiza oficina com Iterpa para demarcação de terras quilombolas". Agência Pará de Notícias, 02/06/2015. Disponible en http://www.agenciapara.com.br/noticia.asp?id ver=113128 (consultado el 11/04/2016). 
6. La carta fue secundada con una recogida de firmas y un acto público que organizó la Associação São Benedito, una asociación que incluye a los ganaderos y agricultores de la comunidad de São Benedito y alrededores, zonas potencialmente afectadas por los reclamos territoriales de los quilombolas.

7. "Los monumentos presentan la colección de héroes, escenas y objetos fundadores. Se colocan en una plaza, un territorio público que no es de nadie en particular pero es de 'todos', de un conjunto social claramente delimitado, los que habitan el barrio, la ciudad o la nación. El territorio de la plaza o el museo se vuelve ceremonial por el hecho de contener los símbolos de la identidad, objetos y recuerdos de los mejores héroes y batallas, algo que ya no existe pero es guardado porque alude al origen y la esencia" (García Canclini 1990: 178).

8. Tras la redacción de este artículo fui informado de que el cañón continúa a día de hoy en la comunidad de Taperú, donde es expuesto en el salón de la escuela local. Según mis informantes, todavía no se han realizado acciones para su estudio o conservación.

\section{Bibliografía}

Arruti, José Mauricio

2008 "Quilombos", en Osmundo Pinho y Livio Sansone (org.), Raça. Novas Perspectivas Antropológicas. Salvador, Editora da Universidade Federal da Bahia: 315-350.

Carneiro da Cunha, Manuela y W. B. de Almeida, Mauro

2000 "Indigenous People, Traditional People, and Conservation in the Amazon", Daedalus, № 2: 315-338.

\section{Cruces,Francisco}

1998 "Problemas en torno a la restitución del patrimonio. Una visión desde la antropología", Política y Sociedad, no 27: 77-87.

De la Torre, Óscar

2013 "Are they really Quilombos? Black peasants, politics, and the meaning of Quilombo in present-day Brazil”, OFO: Journal of Transatlantic Studies, no 1/2: 97-118.

Friedman, Jonathan

2001 Identidad cultural y proceso global. Buenos Aires, Amorrortu.

García Canclini, Néstor

1990 Culturas Híbridas, Estrategias para entrar y salir de la modernidad. México D. F., Grijalbo.

Gluckman, Max

1940 "Analysis of a Social Situation in Modern Zululand", Bantu Studies, no 14: 1-30.

Harris, Mark

2000 Rebellion on the Amazon: The Cabanagem, Race, and Popular Culture in the North of Brazil, 1798-1840. Cambridge, Cambridge University Press.

Hernández Ramírez, Macarena (y Esteban Ruiz Ballesteros)

2011 "Etnogénesis como Práctica. Arqueología y Turismo en el pueblo Manta (Ecuador)", AlBR: Revista de Antropología Iberoamericana, ํo 2: 159-192.

Hoffman, Odile

2000 "La movilización identitaria y el recurso a la memoria (Nariño, Pacífico colombiano)", en Cristóbal Gnecco y Marta Zambrano, Memorias Hegemónicas, Memorias Disidentes. ICAN-Universidad de Cauca: 97-120.

Ibáñez-Bonillo, Pablo

2016 "La conquista del Amazonas en el tablero de la diplomacia europea", Revista de Estudos Amazónicos (en prensa). 
Moreira, Edma Silva

2008 "Movimento Social Amazônico em Defesa de Territórios e de Modos de Vida Rurais: estudo sociológico no Baixo Xingu". Tesis de Doctorado, Universidade Federal do Pará.

Mosquera Rosero-Labbé, Claudia (y Ruby Esther León Díaz) (eds.)

2009 Acciones afirmativas y ciudadanía diferenciada étnico-racial negra, afrocolombiana, palenquera y raizal. Entre Bicentenarios de las Independencias y Constitución de 1991. Bogotá: Universidad Nacional de Colombia.

Pacheco, Pablo (y otros)

2009 Acesso à terra e meios de vida: examinando suas interações em três locais no estado do Pará. Belém, CIFOR.

Quintero Morón, Victoria

2009 Los sentidos del patrimonio. Alianzas y conflictos en la construcción del patrimonio etnológico andaluz. Sevilla, Fundación Blas Infante.

Taylor, Charles

1993 El multiculturalismo y la "política del reconocimiento". México D.F., Fondo de Cultura Económica.

Valcuende del Río, José María

2003 "Algunas paradojas en torno a la vinculación entre patrimonio cultural y turismo", Cuadernos Técnicos. Antropología y Patrimonio: investigación, documentación e intervención: 96-109.

Wade, Peter

1999 "Working Culture: Making Cultural Identities in Cali, Colombia", Current Anthropology, no 4: 449-471. 